\title{
Acute Kidney Injury Following Snake Bite in a Child with Congenital Renal Anomaly
}

\author{
Sudhan Ekam baram ${ }^{1}$, Amish Undani', Vijaya kumar Mahaleengam ${ }^{1}$, Prahlad Nageswaran ${ }^{1}$, Shweta Priyadarshini $^{1}$, Edwin Fernando ${ }^{2}$ \\ ${ }^{1}$ Department of Pediatric Nephrology, ${ }^{2}$ Division of Dialysis Mehta Children's Hospitals, Chennai, India.
}

\section{Abstract}

A 7 year old boy presented with acute kidney injury (AKI) following snake bite despite anti - snake venom (ASV) administration. This was secondary to disseminated intravascular coagulation (DIC) and rhabdomyolysis. He improved with hemodialysis and supportive management. At discharge he had normal renal functions and urine output. The clinical course was suggestive of acute tubular necrosis. The pathogenesis and therapy of snake bite is discussed. This is the first case report of AKI following snake bite in a child with congenital renal anomaly.

Keywords: Acute kidney injury, Anti-snake venom, Hemodialysis, Snake bite.

Corresponding Author: Dr. M.Vijayakumar, Consultant Pediatric Nephrologist, Mehta Children's Hospitals, No.2(e) Mc Nichols Road, $3^{\text {rd }}$ Lane, Chetput, Chennai 600 031, Tamil nadu, India.

Received: August 2018

Accepted: August 2018

\section{Introduction}

Acute kidney injury is an important cause of morbidity and mortality in children with snake bite. This is commonly seen following bites by the viperidae group, the colubridae group and sea snakes. ${ }^{[1]}$ Here, we report a child with reversible acute kidney injury following snake bite.

\section{Case Report}

A 7 year old school boy was referred to our hospital for acute kidney injury management following snake bite in right leg. He reported to our centre 28 hours after snake bite with edema, decreased urine output and hematuria. In view of prolonged whole blood clotting time (WBCT) the child received 10 vials of $\mathrm{ASV}$ at his place. On examination, he was conscious, edematous, pale and jaundiced. His pulse rate was 110 per minute and regular, respiratory rate was 40 per minute and blood pressure (BP) was 160/100 mm $\mathrm{Hg}$. There was local swelling at the site of snake bite. He had basal crackles in both lungs and other systemic examinations were normal. On admission, some salient laboratory data were as follows; hemoglobin $5.6 \mathrm{gm} \%$; total white cell count 12,800cells/mm3; platelet count $30,000 / \mathrm{mm} 3$; reticulocyte count $2.1 \%$; serum creatinine $6.8 \mathrm{mg} / \mathrm{dL}$; lactate dehydrogenase $4257 \mathrm{U} / \mathrm{L}$ (normal 120-300 U/L); creatinine phosphokinase $2461 \mathrm{U} / \mathrm{L}$ (normal <190 U/L); total bilirubin $2.4 \mathrm{mg} / \mathrm{dL}$; indirect bilirubin $1.9 \mathrm{mg} / \mathrm{dL}$; prothrombin time 21 seconds with INR of 1.6; partial thromboplastin time was
28/44 seconds. His peripheral smear showed RBC fragmentation, burr cells, toxic granules and severe thrombocytopenia and urine examination showed nephrotic range proteinuria with hematuria. His ultrasound abdomen was suggestive of crossed fused ectopia of left kidney which was diagnosed only at admission. The above lab parameters revealed that the child was suffering from acute kidney injury with disseminated intravascular coagulation and rhabdomyolysis. His echocardiogram was suggestive of moderate left ventricular dysfunction. Blood and urine cultures were sterile.

He underwent 8 sessions of hemodialysis, received three units of packed red blood cell transfusion, antihypertensives (nifedepine and atenolol) along with supportive management. His urine output increased to more than $2 \mathrm{ml} / \mathrm{kg} /$ hour after 11 days of hospital stay. As his urine output was satisfactory and general conditions improved, diagnosis of acute tubular necrosis was made and hence renal biopsy was deferred. After 17 days of hospital stay, all his metabolic parameters normalised. At discharge his creatinine normalised $(0.7 \mathrm{mg} / \mathrm{dL})$ and only atenolol was continued. At follow-up his serum creatinine was normal $(0.3 \mathrm{mg} / \mathrm{dL})$ and there was no evidence of proteinuria in urinalysis. His BP was stable and hence atenolol was stopped. In view of crossed fused ectopia, dimercaptosuccinic acid scintigraphy was done. This showed mild reduction in function of left kidney with no focal lesions and hence micturating cystourethrography was deferred. It is planned to follow-up the child on a long-term 


\section{Baram et al; Acute Kidney Injury Fallowing Snake Bite}

basis and to decide on angiotensin converting enzyme inhibitors after documenting persistently stable renal functions.

\section{Discussion}

Snake envenomation is a medical emergency and requires prompt treatment. The common systemic manifestations are coagulation disturbances, neurological involvement and acute renal failure. ${ }^{[2]}$ In India, there were 76,948 snake bites reported in the year 2007 with 1,359 deaths. ${ }^{[3]}$ The incidence of proportionate snake bite deaths in India was estimated to be $2.1 / 1000$ in $0-4$ years age group and 28.5/1000 in $5-14$ years age group by a survey conducted in $2001-2003 .{ }^{[4]}$ According to WHO guidelines 2010, the peak age for snake bites is in children and young adults with peak fatality seen in children. ${ }^{[3]}$ The incidence of acute kidney injury is rare. Kulkarni et al in their study followed up 633 children over a period of 7 years. They reported AKI in $1.4 \%$ children and all of them were managed conservatively and none needed dialytic therapy. ${ }^{[2]}$

The kidney is a highly vascularised organ and is susceptible to the venom leading to acute kidney injury. A number of nephrotoxic insults have been implicated in the pathogenesis of acute kidney injury such as nephrotoxicity of venom, hypotension, hemoglobinuria, myoglobinuria, sepsis, DIC, hemodynamic alteration and cell injury mediated by cytokines. $^{[5]}$

More than $90 \%$ of the snake venom is composed of different types of proteins. This venom damages vascular endothelium, mitochondria, peripheral nerve endings, muscles and leads to DIC, neurotoxicity, cardiotoxicity and kidney changes. ${ }^{[6]}$

Paul et al in a study showed the presence of brown coloured urine, $\mathrm{WBCT}>20 \mathrm{~min}$, younger age group and the time interval between ASV administration and bite were the early predictors of acute kidney injury in these patients. ${ }^{[7]}$ The risk factors in our patient were DIC, hematuria and younger age group. The common conditions associated with renal failure are acute tubular necrosis (ATN) and acute cortical necrosis. Usually children with ATN recover and those with diffuse cortical necrosis require dialysis and transplant. ${ }^{[3]}$ Chugh et al reported 8 children with acute kidney injury due to snake bite, of whom 3 died and had documented acute cortical necrosis by histopathology. The remaining 5 children had acute tubular necrosis and they improved. ${ }^{[8]}$ Early intervention and care can significantly improve the prognosis. There are not many studies to determine the progression to chronic kidney disease (CKD). Sinha et al followed up 37 children with acute renal failure over a period of 10 years. Out of them 9 were due to snake bite and 6 of them died. The 3 survivors also had residual renal abnormality in the form of proteinuria and hypertension. ${ }^{[9]}$ Herath et al followed up 54 adult patients bitten by snakes. At the end of 1 year of follow up, 20\% developed CKD and the rest recovered. Patients who underwent renal replacement therapy for prolonged periods (mean duration of 16 sessions) progressed to CKD. At follow-up the creatinine of patients progressing to CKD was higher at the end of 2 months in contrast to the recovery group. ${ }^{[10]}$

It appears that our case study is the first time that snake bite in a congenital renal anomaly is being reported in Indian literature. This association was initially thought to be an acute insult on chronic kidney disease. But subsequent normalization of the renal parameters confirmed it to be an acute insult in a pateint with a congenital renal anomaly.

The initial first aid treatment after snake bite is to reassure, immobilize the affected limb and immediately transfer the child to the hospital. The 20 minute WBCT is the standard test for coagulation. If the blood is still in the liquid state after 20 minutes then this confirms coagulopathy and also points out that the most likely species is Viperine. ${ }^{[11]}$ In our child also the WBCT was prolonged and hence the most likely species was Viperine. After stabilization the next step is to decide on ASV administration. The criteria for its administration depend on systemic and local symptoms. The snake injects the same dose of venom into children and adults; hence the dose of ASV should be same in all age groups. The preferred route for ASV administration is intravenous. It should be given as soon as indicated as it sometimes reverses the abnormality persisting even for 2 weeks. $^{[3]}$

The initial dose of ASV is 8-10 vials with maximum of 25 vials which is decided based on the condition of the child. ${ }^{[11]}$ ASV is repeated in children who have recurrence of blood incoagulability after 6 hours of initial dose or if bleeding after 1-2 hours. In children who have deteriorating neurotoxic or cardiovascular signs 1-2 hours after ASV administration also require repeat doses. Adequate hydration and alkalinization of urine is recommended in rhabdomyloysis and other measures include treatment of electrolyte disturbances, fresh frozen plasma and packed red blood cell transfusion in coagulopathic states along with treatment of infection. Dialysis is indicated in adults presenting with clinical uremia, symptomatic acidosis, fluid overload states, creatinine $>4 \mathrm{mg} / \mathrm{dL}$, urea $>130 \mathrm{mg} / \mathrm{dL}$ and potassium $>7 \mathrm{mEq} / \mathrm{L}$ and probably in children if creatinine $>$ $3 \mathrm{mg} / \mathrm{dL}$ and potassium $>5.5 \mathrm{mEq} / \mathrm{L} .^{[3]}$

\section{Conclusion}

Snake bite being a common scenario in India, timely referral and appropriate management is necessary in AKI, not only to save the lives of the affected children but also to prevent them from progressing to chronic kidney disease.

\section{$\underline{A C K N O W L E D G E M E N T}$}

Hemodialysis and Pediatric Intensive Care Unit staff of Mehta Children's Hospitals for hemodialysis care and intensive monitoring during hospitalization. 


\section{References}

1. Patil TB, Bansod YV, Patil MB. Snake bite induced Acute Renal Failure: A Study of Clinical Profile and Predicators of Poor Outcome. World Journal of Nephrology and Urology. 2012;1:59-65.

2. Kulkarni ML, Anees S. Snake venom poisoning: Experience with 633 cases. Indian Pediatr. 1994; 10:1239-1243.

3. WHO SEARO. Guidelines on Management of Snake-bites. New Delhi: WHO Regional Office for South-East Asia; 2010. (cited November 2012) Available: http://www.searo.who.int/LinkFiles/ BCT_snake_bite_guid elines.pdf

4. Mohapatra B, Warrell DA, Suraweera W, Bhatia P, N Dhingra, Jotkar RM et al. Snakbite mortality in India: a nationally representative mortality survey. PLoS Negl Trop Dis. 2011; 5: e1018

5. Cruz LS, Vargas R, Lopes AA. Snakebite envenomation and death in the developing world. Ethn Dis. 2009;19: S1-42-46.
6. Warrell DA. Snake Bite. Lancet 2010; 375:77-88.

7. Paul J, Dasgupta S. Early prediction of acute kidney injury by clinical features of snakebite patients at the time of hospital admission. N Am J Med Sci. 2012;4(5):216-20.

8. Chugh KS, Aikat BK, Sharma BK, Dash SC, Mathew MT, Das KC. Acute renal failure following snake bite. Am J Trop Med Hyg. 1975;24:692-7.

9. Sinha R, Nandi M, Tullus K, Marks SD, Taraphder A. Ten year follow up of children after acute renal failure from a developing country. Nephrol Dial Transplant. 2009;24:829-33

10. Herath HM, Wazil AW, Abeysekara DT, Jeewani ND, Weerakoon KG, Ratnatunga NV et al. Chronic kidney disease in snake envenomed patients with acute kidney injury in SriLanka: a descriptive study. Postgrad Med J. 2012;88:138-42.

11. Simpson ID. The Pediatric management of Snakebite: The National Protocol. Indian Pediatr. 2007;44 (3):173-176.

Copyright: (C) the author(s), publisher. Asian Journal of Clinical Pediatrics and Neonatology is an Official Publication of "Society for Health Care \& Research Development". It is an open-access article distributed under the terms of the Creative Commons Attribution NonCommercial License, which permits unrestricted non-commercial use, distribution, and reproduction in any medium, provided the original work is properly cited.

How to cite this article: Ekam baram S, Undani A, Mahaleengam V, Nageswaran P, Priyadarshini S, Fernando E. Acute Kidney Injury Following Snake Bite in a Child with Congenital Renal Anomaly. Asian J. Clin. Pediatr. Neonatol.2018;6(3):4-6.

DOI: dx.doi.org/10.21276/ajcpn.2018.6.3.2

Source of Support: Nil, Conflict of Interest: None declared. 